\title{
PERANCANGAN MEDIA VIDEO DESAIN INTERIOR SEBAGAI SALAH SATU PENUNJANG PROMOSI DAN INFORMASI DI PT. WANS DESAIN GROUP
}

\author{
Wahyu Hidayat \\ Fauzi Maafuf \\ Saeful Bahari
}

Email :wahyu.hidayat@raharja.info, fauzan.manafil@raharja.info, saeful.bahri@ raharja.info

\begin{abstract}
Interior design and decoration for this often happens in common where both of them like in a the same profession. Because they both have the same i.e. want to give a sense of sense of beauty and comfort in every room. The Interior decoration is only a small part of the task is an interior designer. Interior designers and interior decorators alike have an important role in the enhancement of the quality of the room, although both are different. As for the field that will be needed at a company or organization to design a promotional media in promoting and informing a product item or service to the community. So the company becomes taxable in the community and in promoting a product or a simulation of the design you want. To promote it field examples like design, Interior, Multimedia, and animations
\end{abstract}

Keywords: Design, Decor, Interior, Animation

\begin{abstract}
ABSTRAKSI
Desain Interior dan dekorasi selama ini sering terjadi kesamaan dimana keduanya seperti dalam suatu profesi yang sama. Karena keduanya sama-sama memiliki yang sama yaitu ingin memberikan rasa rasa keindahan dan kenyaman di setiap ruangan. Dekorasi Interior hanya bagian kecil dari tugasnya seorang desainer interior.Desainer interior dan dekorator interior sama-sama memiliki peran yang penting dalam meningkatan kualitas ruangan, meskipun keduanya berbeda. Adapun bidang ini yang nantinya akan diperlukan pada suatu perusahaan atau organisasi untuk mendesain sebuah media promosi dalam mempromosikan dan menginformasikan suatu produk barang atau jasa kepada masyarakat. Sehingga perusahaan tersebut menjadi di kena oleh masyarakat dan di promosikan suatu produknya atau simulasi dari desain yang inginkan. Bidang untuk mempromosikannya contohnya seperti desain, Interior,Multimedia, dan Animasi.
\end{abstract}




\section{Kata Kunci: Design, Dekorasi, Interior,Animasi}

\section{PENDAHULUAN}

Di era globalisasi membawa dua dampak, di satu sisi dapat meningkatkan kesempatan di bidang ketenagakerjaan, di sisi lain terhadap dunia usaha kompetisi semakin tajam dan ketat, oleh karena itu dibutuhkan strategi yang tepat dalam mencapai keberhasilan di bidang dunia usaha.

Dalam memasarkan sebuah produk pihak perusahaan membutuhkan program promosi yang memiliki media sarana yang efektif. Dari sarana media yang telah digunakan setiap periode yang telah ditentukan tentunya telah dilakukan evaluasi secara seksama agar program promosi waktu mendatang mempunyai nilai yang lebih baik dibandingkan waktu sebelumnya.

PT. Wans Design Group didirikan pada bulan Oktober 2002, di jakarata barat. PT Wans Design Grup Design ini merupakan hasil kerjasama antara Ir. Hans Kurniawan yang sekarang menjabat sebagai Direktur Utama, dengan EMMI yang sekarang menjabat sebagai desainer dan Agung Nugroho yang menjabat sebagai Direktur produksi di PT Wans Design Grup PT. Wans Design Group merupakan sebuah perusahaan yang bergerak di bidang pembangunan dan jasa. Sebagai kegiatan usaha yang mencakup pembangunan gedung seperti perumahan, apartemen, rumah sakit dan lain - lain yang bertindak sebagai pengembang maupun yang mencakup jasa seperti desain interior, exterior dan konsultasi bidang teknik.

\section{Pengertian Media}

Menurut Maimunah dkk, Media adalah sarana untuk menyampaikan pesan atau informasi kepada publik dengan menggunakan berbagai unsur komunikasi grafis seperti teks, gambar atau foto, Vol.5 No.3-Mei 2012.

\section{Pengertian Video}

Menurut Melvy Ayuningtias, 2011:7 Video merupakan gabungan gambar-gambar mati yang dibaca berurutan dalam suatu waktu dengan kecepatan tertentu.

\section{Pengertian Interior}

Menurut Ching 2013: 160 interior sebuah bangunan dibentuk oleh elemen-elemen arsitektur dari struktur dan pembentuk ruangnya yang terdiri atas kolom, dinding, lantai, dan plafon. 
Elemen-elemen tersebut memberi bentuk pada bangunan, memisahkannya dengan ruang luar, dan membentuk pola tatanan ruang interior.

\section{Unsur - unsur Desain Interior}

Menurut Suptandar, 2010: 70. Unsur-unsur adalah alat atau bahan baku seperti cat adalah dasar-dasar untuk seorang pelukis.

\section{Pengertian Promosi}

Menurut Lukiati Komala, 2010:54-59. Promosi adalah suatu bentuk komunikasi pemasaran. Yang dimaksud dengan komunikasi pemasaran adalah aktivitas pemasaran yang berusaha menyebarkan informasi, mempengaruhi atau membujuk dan mengingatkan pasar sasaran atas perusahaan dan produknya agar bersedia menerima dan loyal pada produk yang ditawarkan perusahaan yang bersangkutan.

\section{Pengertian Informasi}

Yakup, 2012:8. Informasi (information) dapat didefinisikan sebagai berikut : "Informasi adalah data yang diolah menjadi bentuk yang lebih berguna dan lebih berarti bagi yang menerimannya, informasi disebut juga data yang diproses atau data yang memiliki arti”.

\section{Definisi Multimedia}

Menurut Vaughan, (2012:2). Multimedia merupakan kombinasi teks, seni, suara, gambar, animasi, dan video yang disampaikan dengan komputer atau dimanipulasi secara digital dan dapat disampaikan atau dikontrol secara interaktif.

\section{Definisi Audio Visual}

Menutut Atmohoetomo, (2010:4). Audio visual merupakan gabungan dari dua kata yaitu audio yang berarti suara dan visual yang berarti gambar, atau dengan kata lain menjelaskan, "Audio Visual adalah alat peraga yang dapat dilihat dan didengar dalam hal ini gambar yang bergerak menimbulkan suara."

\section{Definisi Storyboard}

Menurut Suyanto, (2012:20). Storyboard adalah sebuah teknik shooting management. Disini dibuat daftar pengambilan gambar pada setiap adegan, dan divisualisasikan dalam bentuk sketsa gambar atau storyboard jika diperlukan. 


\section{Definisi Google Skechup}

SketchUp merupakan sebuah program pemodelan 3D yang dirancang untuk arsitek, insinyur sipil, pembuat film, game developer dan profesi terkait. Aplikasi ini dirancang untuk menjadi lebih mudah digunakan dibandingkan program CAD 3D.

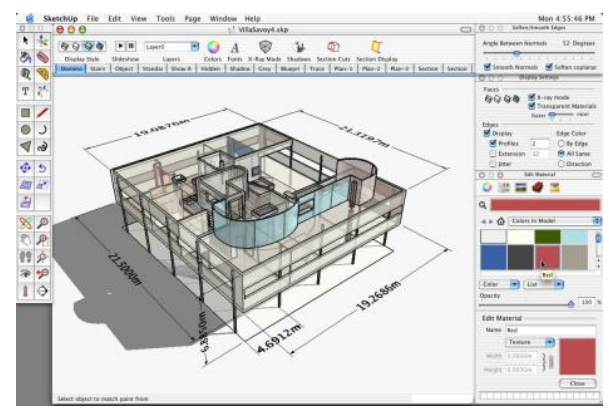

Gambar Google Skechup

\section{Definisi Lumion}

Lumion adalah program yang indah, yang memungkinkan kita untuk membuat skenario 3D kita dengan kualitas real-time rendering yang luar biasa. Hal ini juga memungkinkan kita untuk mengimpor objek dan pengaturan dari program lain seperti google sketchup.

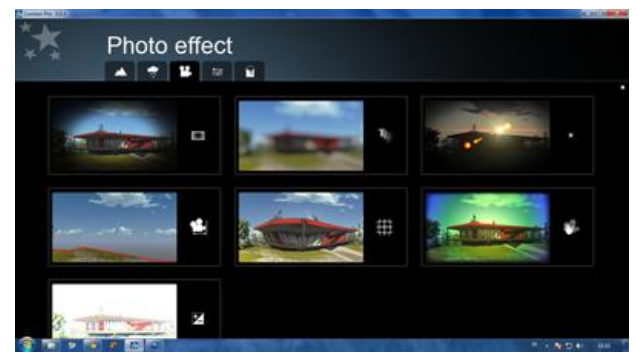

\section{Gambar Lumion}

\section{Definisi Photoshop CS3}

Menurut Abdul Razaq,(2011,44-50) Adobe Photoshop CS3 adalah suatu perangkat lunak canggih yang dapat Anda gunakan untuk membuat, menyunting dan memanipulasi tampilan termasuk mengoreksi warna dan memberi efek tampilan atas sebuah gambar atau photo, hasil dari program ini merupakan sebuah gambar / image, di dalam komputer grafis terbagi menjadi 2 kelompok yaitu gambar Bitmap dan gambar Vektor. 


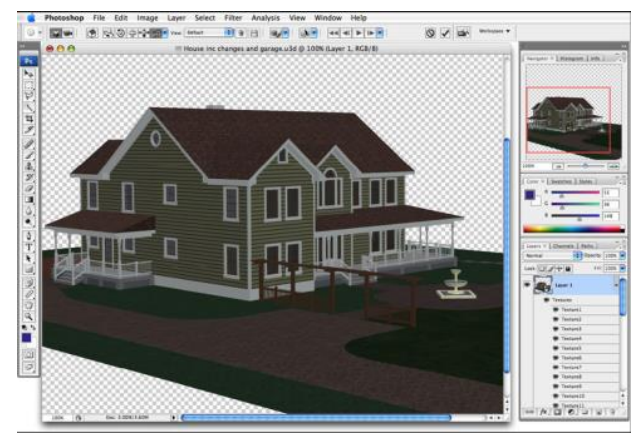

Gambar Photoshop CS3

\section{Market Segmentation}

Geografi : Wilayah Jabodetabek

Demografi $\quad: \bullet$ Jenis Kelamin $\quad$ :Pria \& Wanita

- Kelas Ekonomi : Menengah Atas

Menengah

- Sasaran : : Perusahaan

2. Devolaper

Psikografi : Calon Customer, relasi dan masyarakat umumnya khususnya di daerah jakarta untuk mengetahui informasi lebih detail tentang PT. Wans Design Group.

\section{Preproduction}

Ada beberapa langkah Preproduction dalam pembuatan Media video interior PT. Wans Design Group, dimulai dari observasi lapangan dengan mengumpulkan data-data yang diperlukan, kemudian yang dituangkan dalam sebuah ide/gagasan secara sistematis agar menghasilkan pesan dari media video interior itu sampai kepada penonton, lalu diikuti dengan pembuatan sinopsis, Script Writting dan Storyboard.

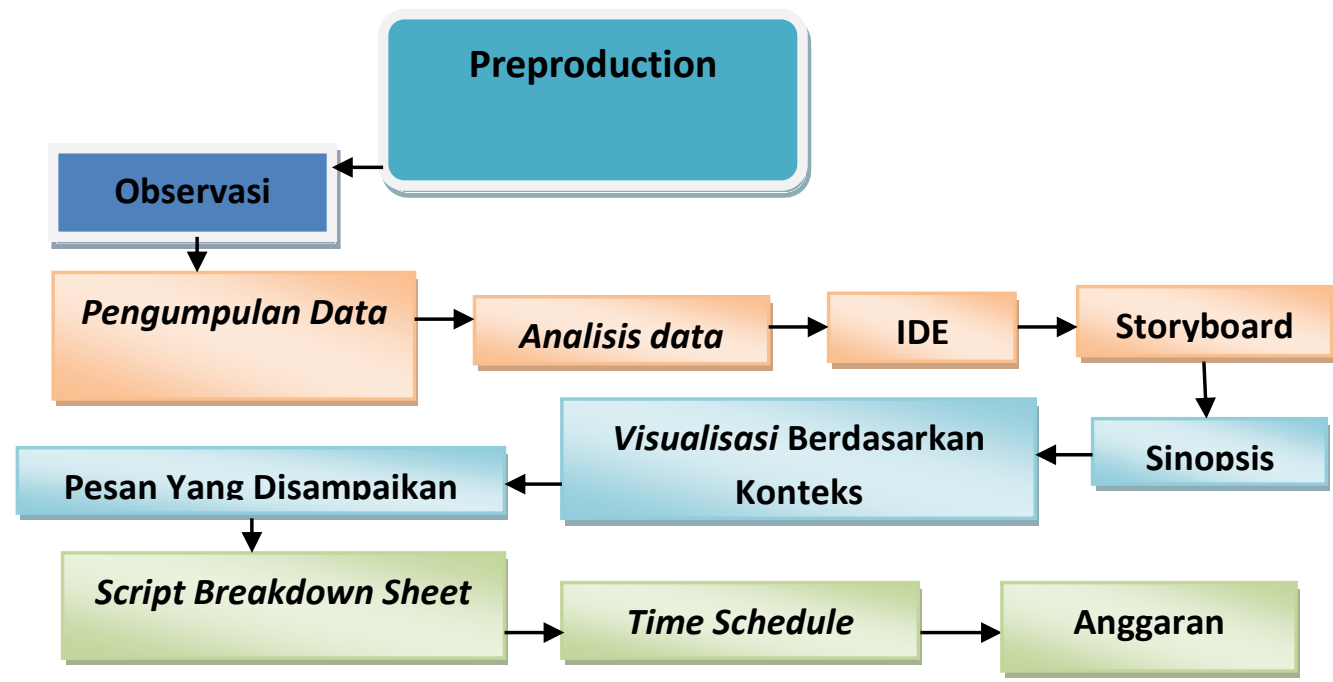

Bagan Preproduction 


\section{Layout Kasar}

\section{Scene 1}

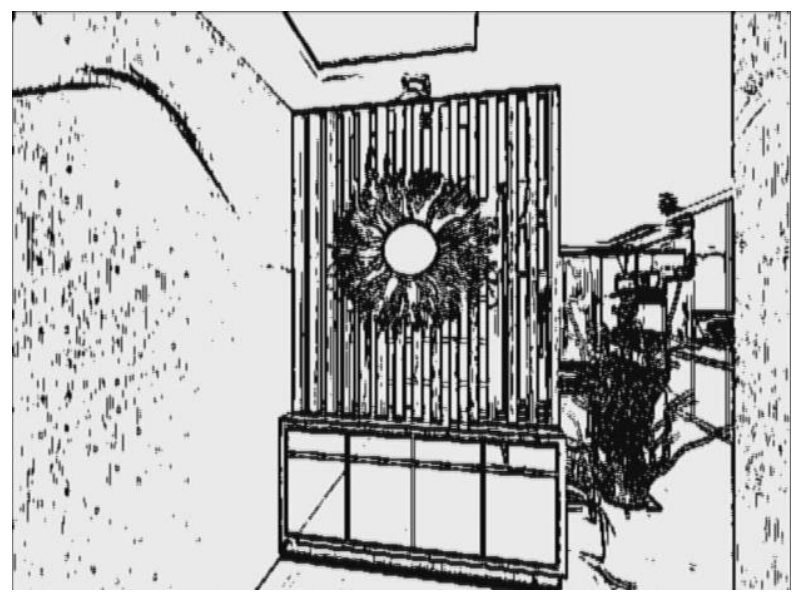

Scene 2

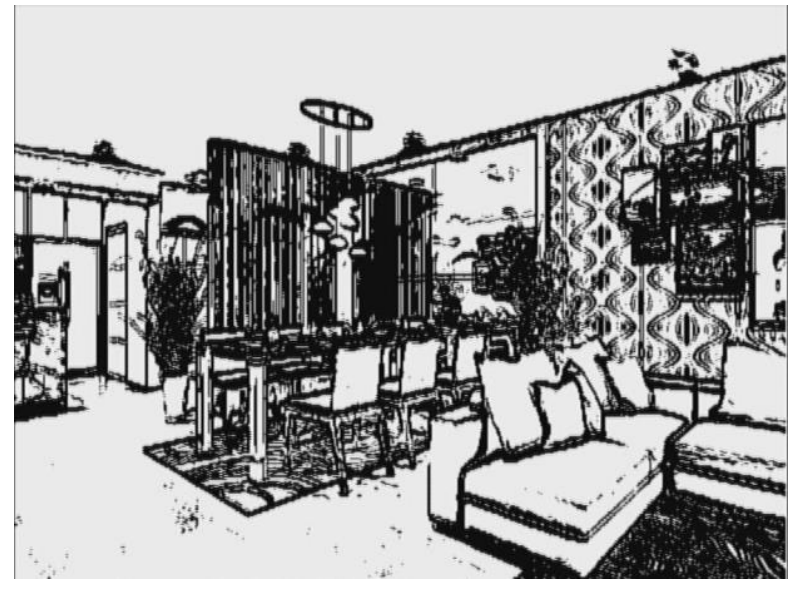

Scene 3

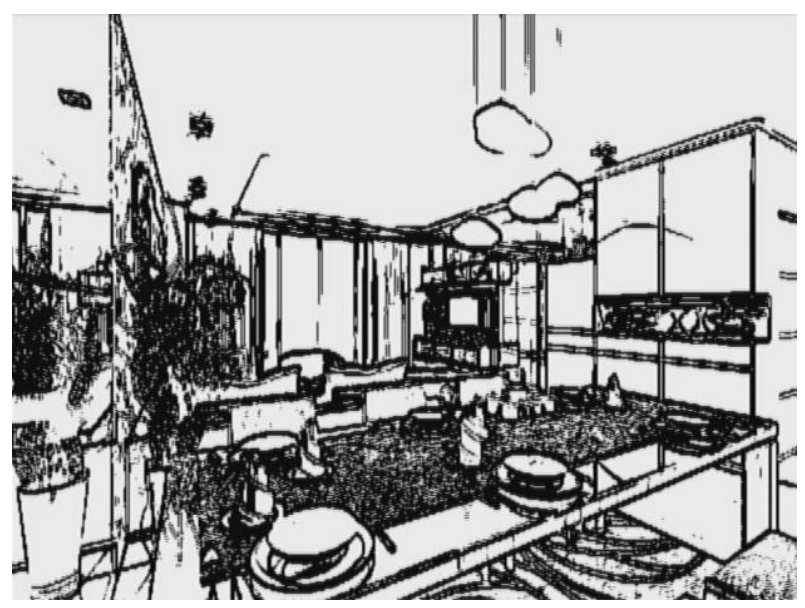

\section{Full Shot(FS)}

Menggambarkan ruangan apartemen video Desain Interior gambar pintu masuk Living Room

\section{Full Shot(FS)}

Menggambarkan situasi, video Desain Interior gambar depan Living Room yang bersih dan minimalis.

\section{Full Shot(FS)}

Menggambarkan situasi, video Desain Interior gambar dari samping Living Room yang bersih dan minimalis. 
Scene 4

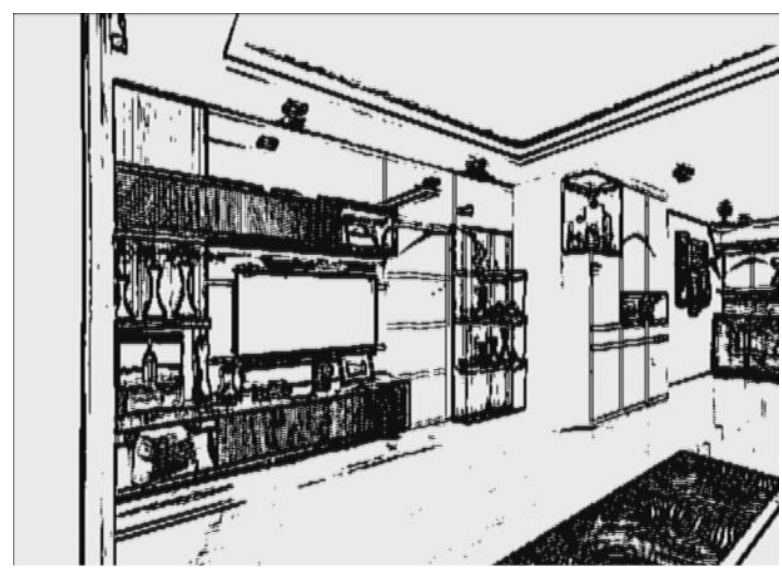

Scene 5

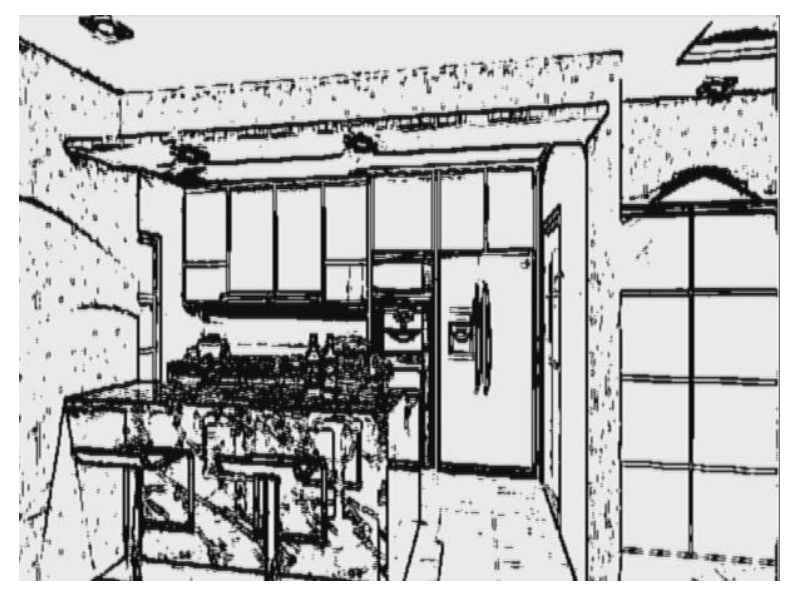

Scene 6

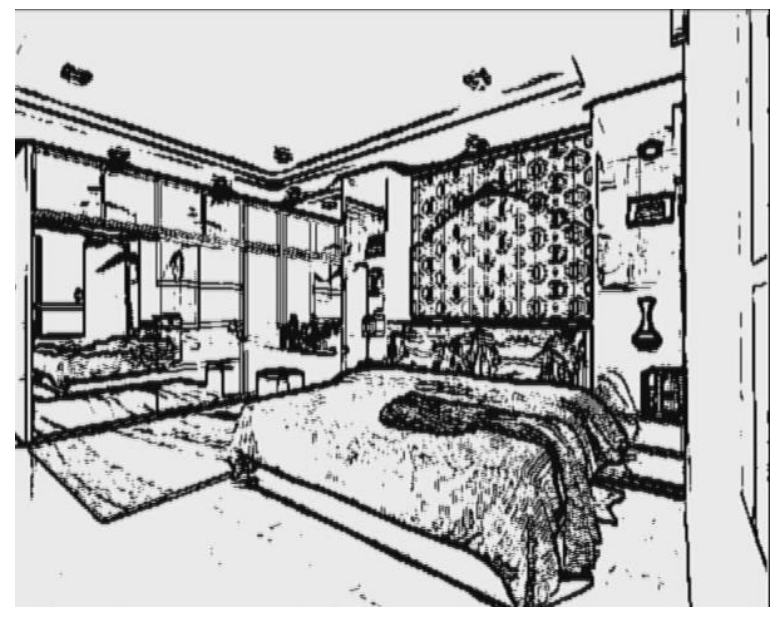

\section{Full Shot(FS)}

Menggambarkan situasi, video Desain Interior ruang TV Living Room yang bersih dan minimalis.

\section{Full Shot(FS)}

Menggambarkan situasi, video Desain Interior Kitchen yang bersih dan minimalis.

\section{Full Shot(FS)}

Menggambarkan situasi, video Desain Interior Kamar Tidur Utamayang bersih dan minimalis. 
Scene 7

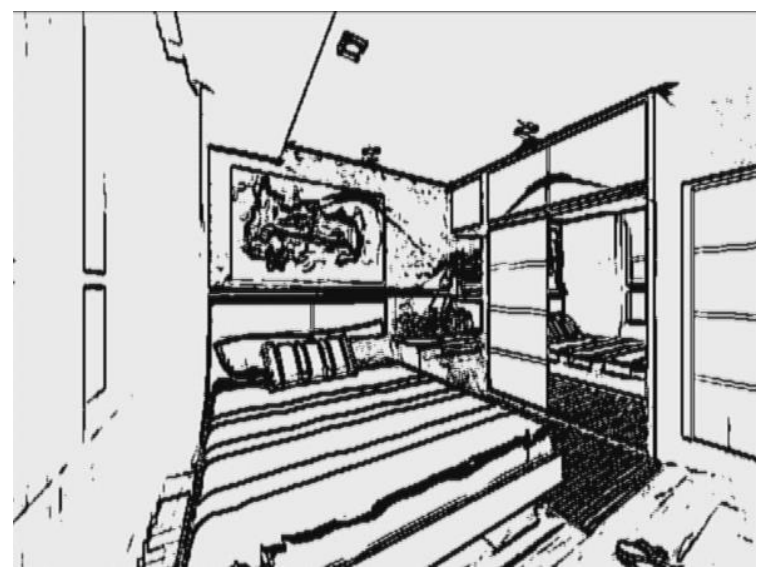

Scene 8

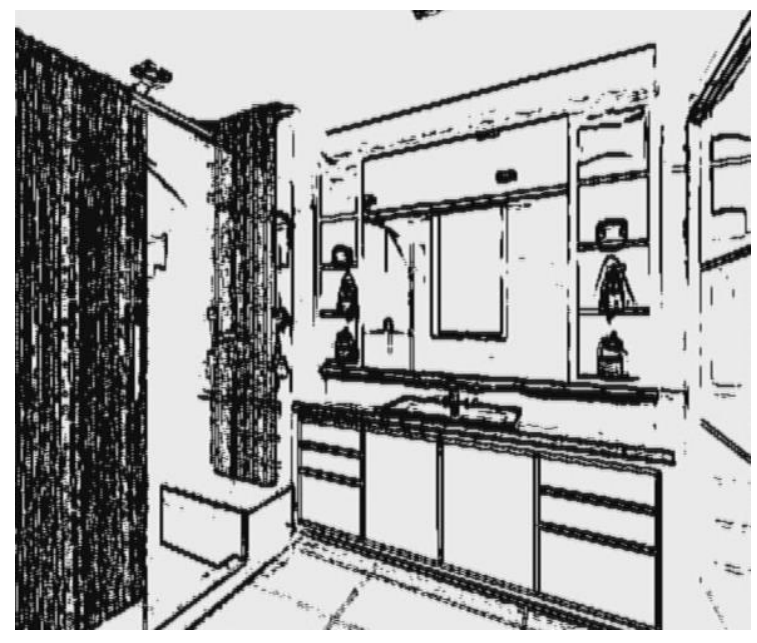

Scene 9

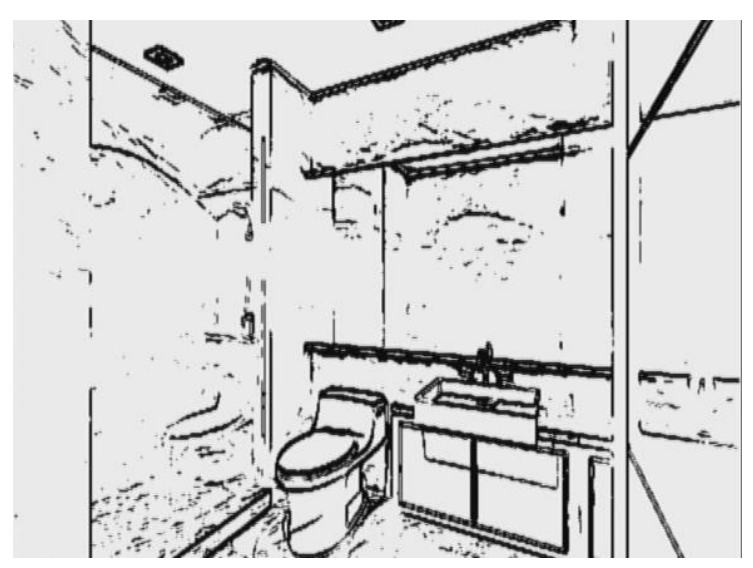

\section{Full Shot(FS)}

Menggambarkan situasi, video Desain Interior kamar Tidur anak yang bersih dan minimalis.

\section{Full Shot(FS)}

Menggambarkan situasi, video Desain Interior Kamar mandi Utama yang bersih dan minimalis.

\section{Full Shot(FS)}

Menggambarkan situasi, video Desain Interior Kamar mandi anak yang bersih dan minimalis. 


\section{Production}

Production adalah proses pengambilan gambar atau shooting video untuk pewujudan rumusan dari tahap preproduction dalam bentuk skenario, naskah, dan storyboard yang telah dibuat. Pada tahap production semua unsur teknis dan kreatif seperti naskah, actor, sinematografi dan suara bergabung dibawah pengawasan kreatif sutradara.

\section{Storyboard}

\section{Scene 1}

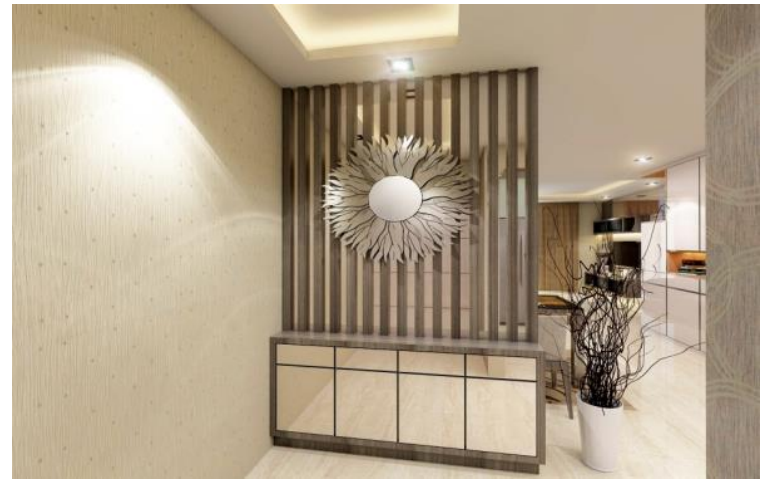

\section{Full Shot(FS)}

Menggambarkan ruangan apartemen video Desain Interior gambar pintu masuk Living Room

\section{Scene 2}

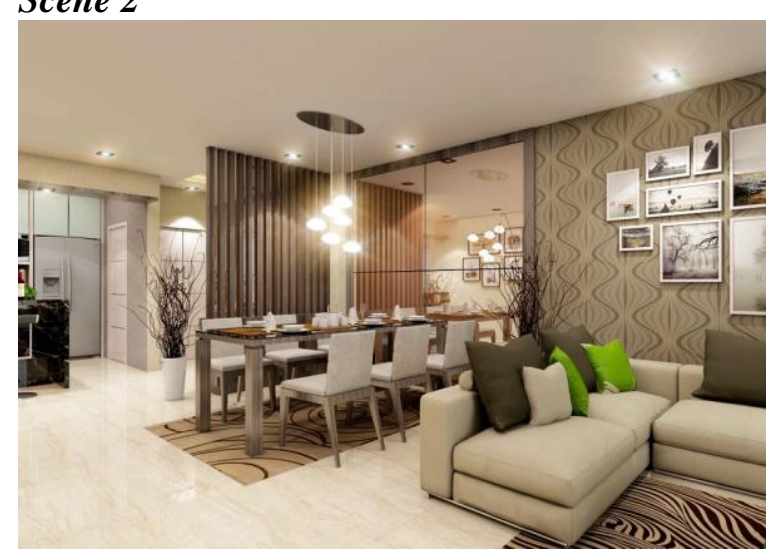

\section{Full Shot(FS)}

Menggambarkan situasi, video Desain Interior gambar depan Living Room yang bersih dan minimalis.

\section{Scene 3}

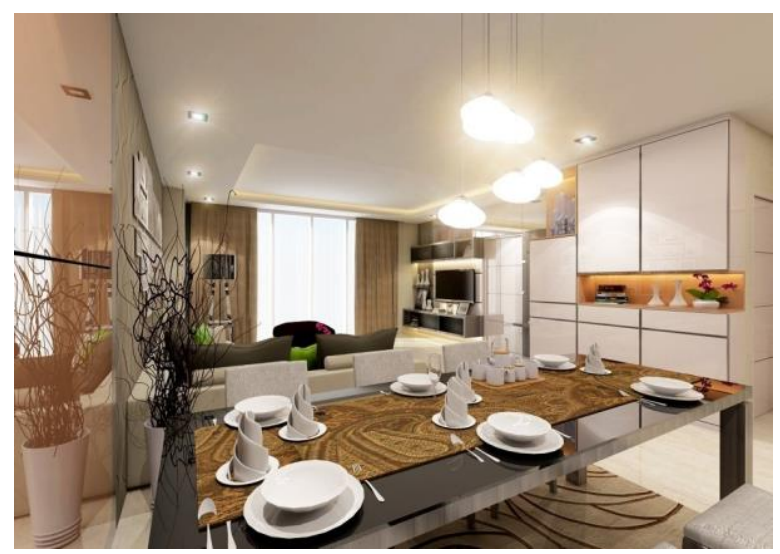

\section{Full Shot(FS)}

Menggambarkan situasi, video Desain Interior gambar dari samping Living Room yang bersih dan minimalis. 


\section{Scene 4}

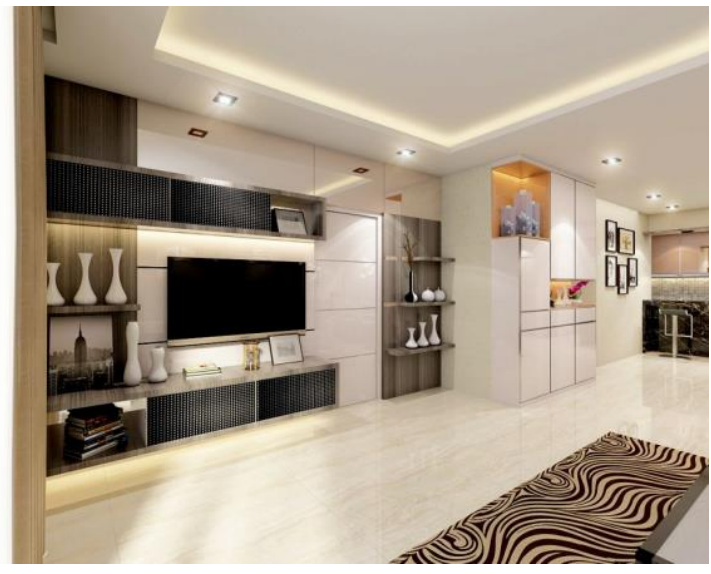

\section{Full Shot(FS)}

Menggambarkan situasi, video Desain Interior ruang TV Living Room yang bersih dan minimalis.

\section{Scene 5}

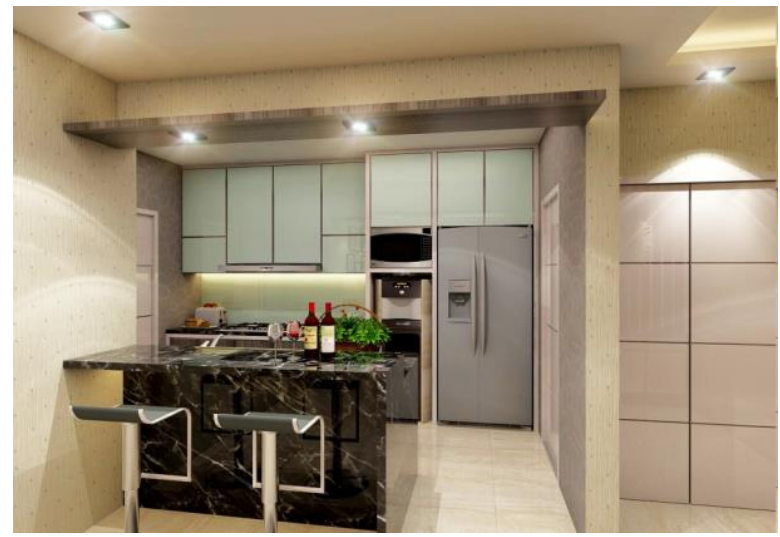

\section{Full Shot(FS)}

Menggambarkan situasi, video Desain Interior Kitchen yang bersih dan minimalis.

\section{Scene 6}

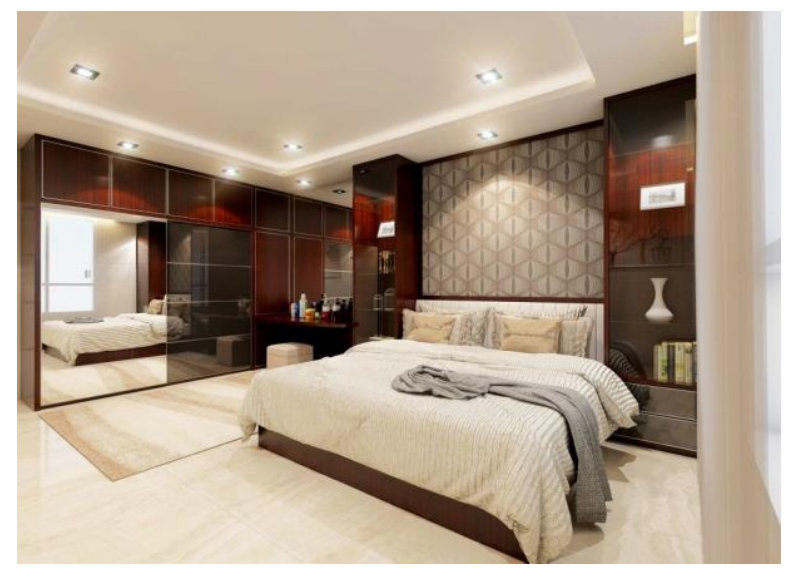

\section{Full Shot(FS)}

Menggambarkan situasi, video Desain Interior Kamar Tidur Utamayang bersih dan minimalis. 


\section{Scene 7}

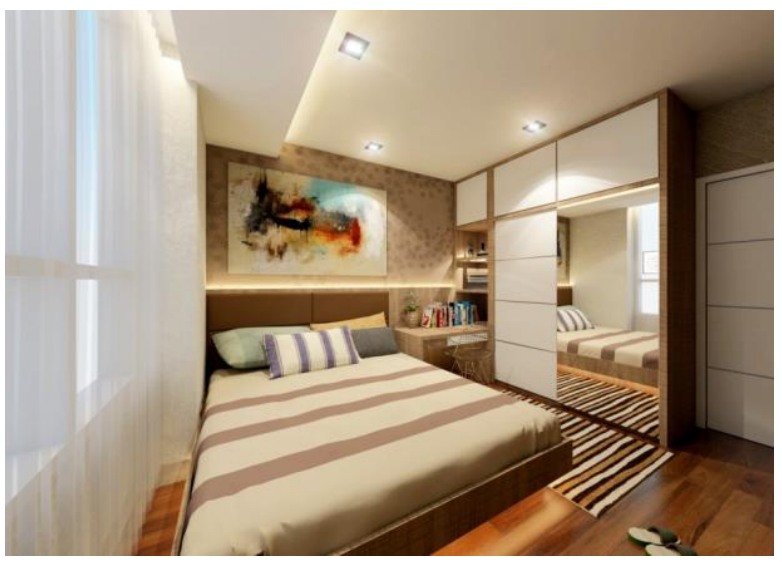

\section{Full Shot(FS)}

Menggambarkan situasi, video Desain Interior kamar Tidur anak yang bersih dan minimalis.

\section{Scene 8}

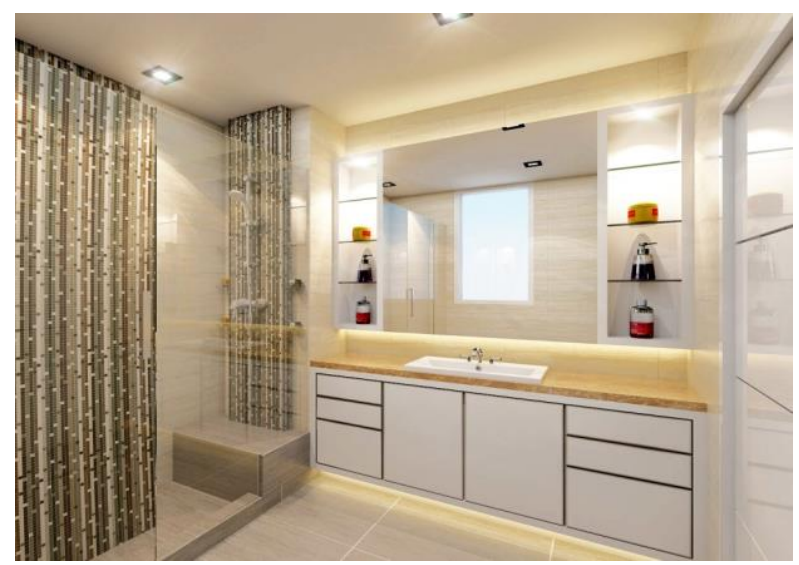

\section{Full Shot(FS)}

Menggambarkan situasi, video Desain Interior Kamar mandi Utama yang bersih dan minimalis.

\section{Scene 9}

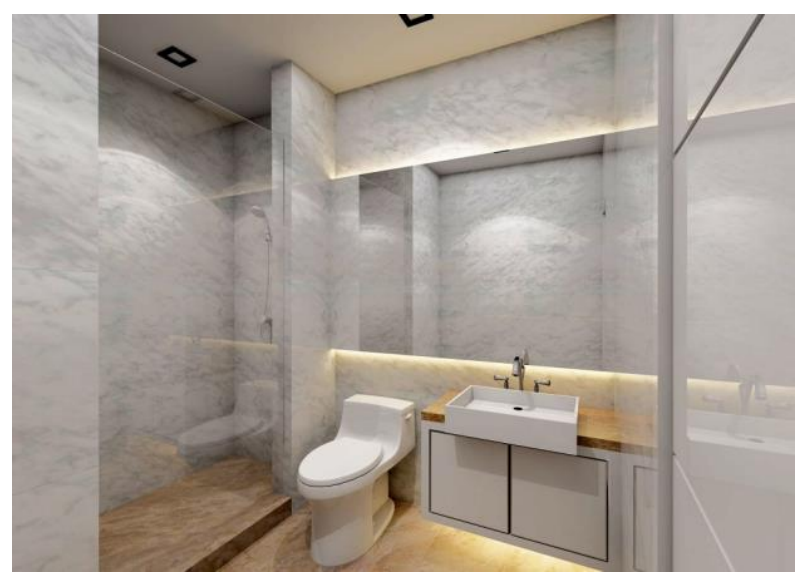

\section{Full Shot(FS)}

Menggambarkan situasi, video Desain Interior Kamar mandi anak yang bersih dan minimalis. 


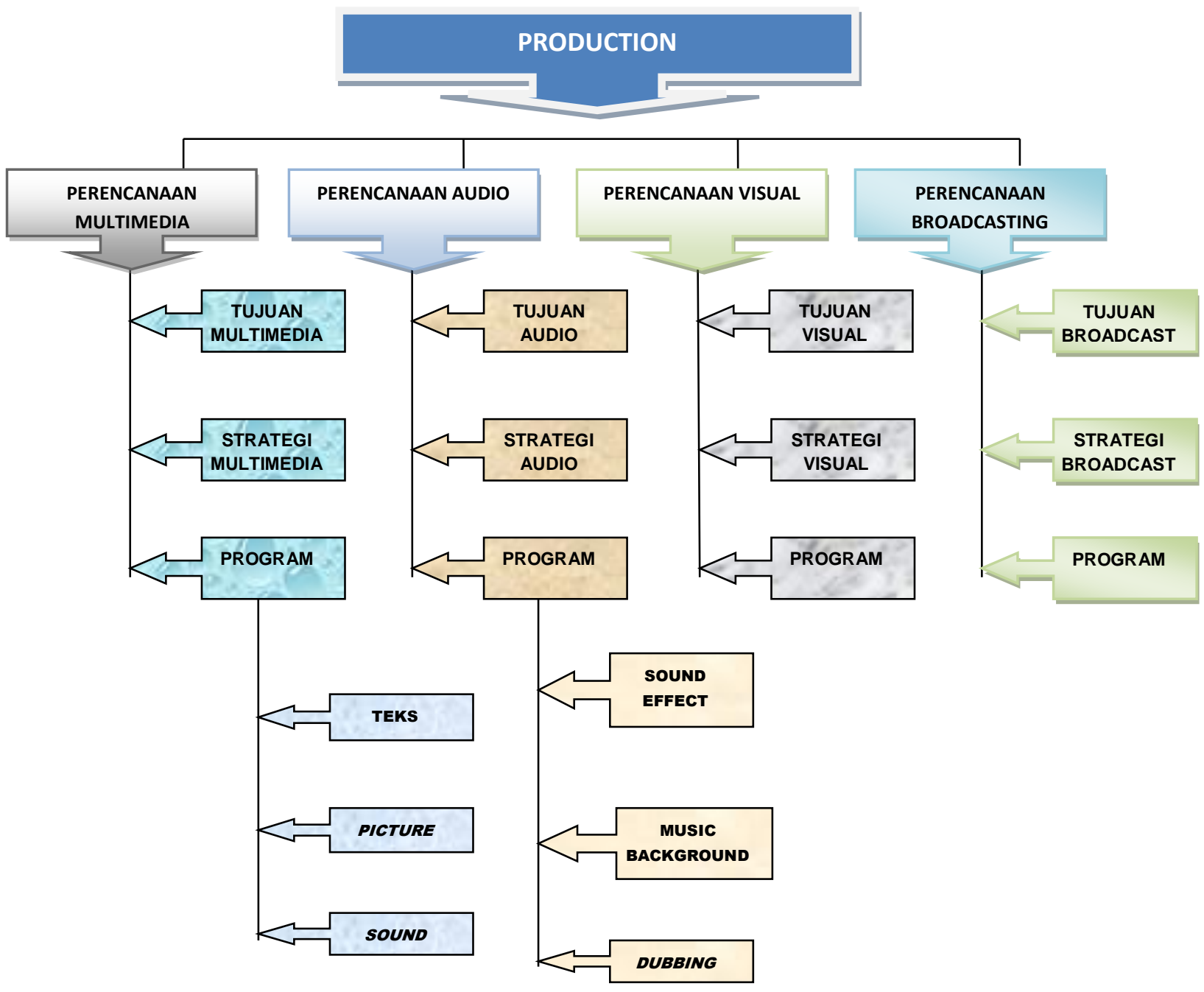

Bagan Preproduction 


\section{Postproduction}

Tahap postproduction adalah proses finishing sebuah karya sampai menjadi sebuah video yang utuh dan mampu menyampaikan sebuah cerita atau pesan kepada audience.

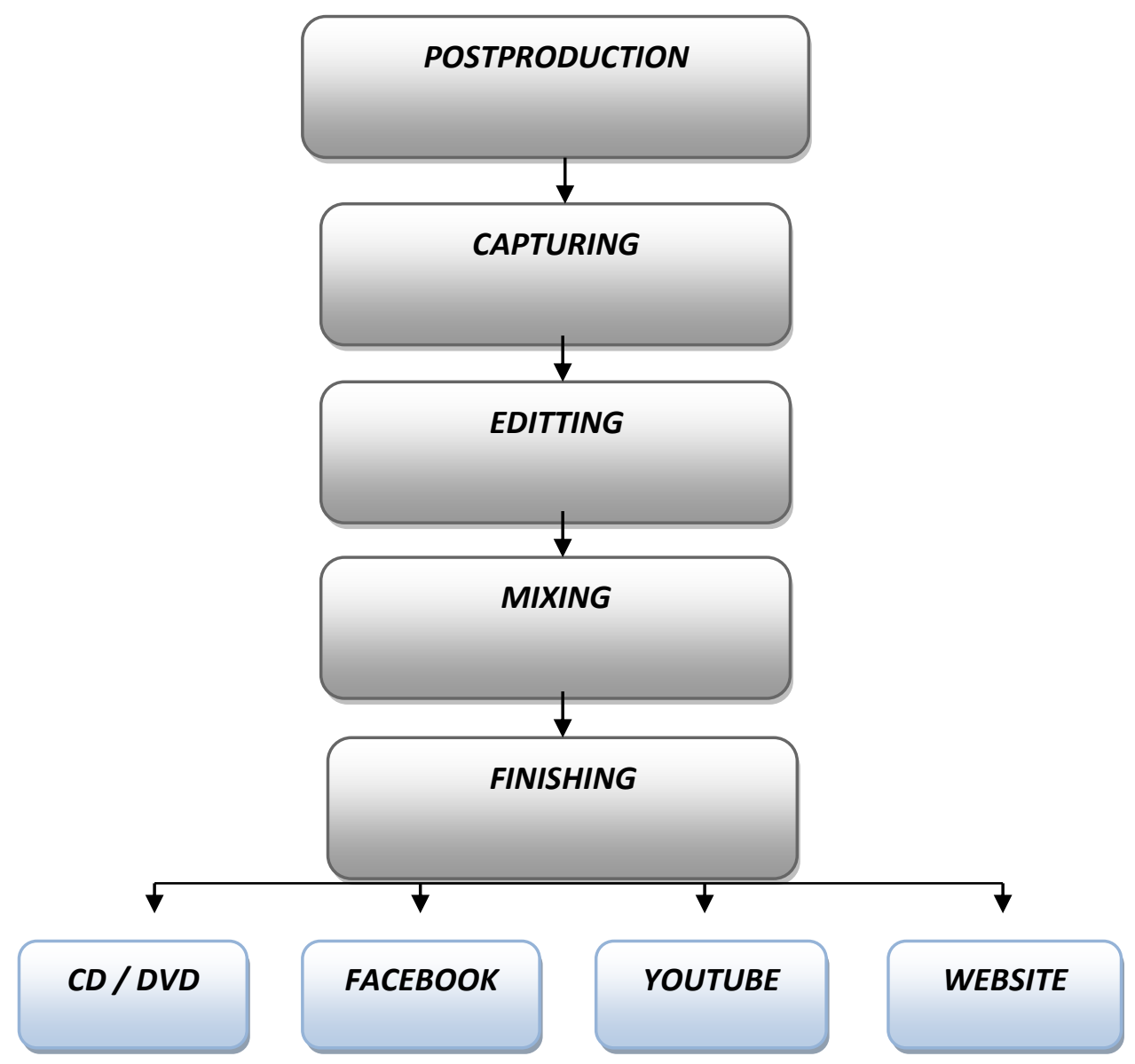




\section{Literature Review}

1. Penggunaan Aplikasi Multimedia Pembelajaran Topologi Jaringan Komputer Berbasis Macromedia Flash Untuk Meningkatkan Hasil Belajar Mata Pelajaran Tik Siswa Kelas Xi Sma N 1 Godean adalah salah satu Jurnal yang dibuat oleh Bisono Indra Cahya sebagai mahasiwa Universitas Negeri Yogyakarta. Penelitian ini menjelaskan tentang kurangnya media publikasi berbentuk Macromedia Flash yang berbentuk video Belajar Mata Pelajaran Tik Siswa Kelas Xi Sma N 1 Godean. Maka dari itu saya membuat Macromedia Flash berbasis multimedia untuk Belajar Mata Pelajaran Tik Siswa Kelas Xi Sma N 1 Godean.

2. Teknologi Media Pembelajaran Sejarah Melalui pemanfaatan Multimedia Animasi Interaktif adalah salah satu jurnal yang di buat oleh Ilham Eka Putra, S.Kom., M.Hum sebagai dosen Sistem Informasi STMIK Indonesia Padang. Penelitian ini menjelaskan tentang kurangnya media publikasi berbentuk Animasi yang berbentuk Teknologi Media Pembelajaran Sejarah Melalui pemanfaatan Multimedia Animasi Interaktif.

3. Pembuatan Film Animasi Pendek "Dahsyatnya Sedekah" Berbasis Multimedia Menggunakan Teknik 2d Hybrid Animation Dengan Pemanfaatan Graphic adalah salah satu jurnal yang di buat oleh Chabib Syafrudin, Wahyu Pujiyono sebagai mahasiswa Universitas Ahmad Dahlan yogyakarta. Penelitian ini menjelaskan tentang kurangnya media publikasi berbentuk film animasi yang berbentuk Dahsyatnya Sedekah

4. Efektifitas animasi multimedia melalui model pembelajaran kooperatif tipe student team Achievement Division (STAD) terhadap aktivitas belajar dan penguasaan materi pokok sistem peredaran darah oleh siswa (Studi Eksperimen pada Siswa Kelas XI IPA Semester Ganjil SMA Negeri 1 Sumberejo Tahun Pelajaran 2012/2013) adalah salah satu Skripsi yang dibuat oleh Nuris Mukhton sebagai mahasiswa Universitas Lampung 


\section{Kesimpulan}

Setelah penulis melakukan penelitian pada PT Wans Design Grup, penulis berkesimpulan bahwa Media Desain Interior yang dikemas dalam bentuk Audio Visual (Video) sangat di perlukan bagi PT Wans Design Grup khususnya di bidang propeti, kitchen set juga interior desain,dan dengan adanya Media Desain Interior tersebut dapat meningkatkan suatu image atau citra dari masyarakat agar tertarik dengan produk dari PT Wans Design Grup.

Dalam pembuatan media Desain Interior yang baik, harus memperhatikan faktor-faktor yang berhubungan dengan PT Wans Design Grup yang bersangkutan.Dalam hal ini penulis menyesuaikan dengan keinginan stakeholder, mulai dari pembuatan Desain, Animasi, tampilan, isi pesan dan penutup. Hal ini bertujuan untuk memperkuat media Desain audio viual (video) dalam mempromosikan Produk interior desain dan mengajak masyarakat untuk dapat berlangganan dan menjadi pelanggan tetap dari PT Wans Design Grup.

\section{DAFTAR PUSTAKA}

1. Abdul Razaq, 2011 The Magic of Movie Editing, Media Kita, Jakarta,

2. Atmohoetomo, 2013 Media Iklan dan Periklanan, Jakarta

3. Ching, 2014 Konsep Dasar Perancangan Interior, Jakarta,

4. Lukiati Komala, 2010 Media Informasi animasi, Bandung,

5. Maimunah, Lusyani Sunarya, Nina Larasati. 2012. Media Company Profile Sebagai Sarana Penunjang Informasi dan Promosi. Journal CCIT Vol.5 No.3 - Mei 2012. Tangerang: Perguruan Tinggi Raharja.

6. Melvy Ayuningtias, 2011 Berkarier di bidang Broadcasting, Media Pressindo, Yogyakarta

7. Suptandar, 2010 Jenis-jenis Media interior desain, Jakarta.

8. Suyanto, 2014 Media Informasi animasi, Bandung.

9. Vaughan, 2012 Broadcasting To Be Broadcaster, Yogyakarta, Graha Ilmu.

10. Yakup, 2013 Media Informasi Manajemen, Media Pressindo, Yogyakarta. 